\title{
The distinct pathogenesis of IgG4 Mickulicz's disease and Sjogren's syndrome in Japan; the role of IL-21 and IL-6
}

\author{
Robert Irving Fox
}

Maehara et al present an interesting study on 'Interleukin-21 contributes to germinal centre formation and immunoglobulin G4 production in IgG4-related dacroadenitis and sialoadenitis, so-called Mickulicz's disease (MD)'. ${ }^{1}$ They have studied 12 Japanese patients with $\mathrm{MD}$ (IgG4-DS), 15 with Sjogren's syndrome (SS) and 15 healthy controls. The labial salivary biopsies (LSB) of 15 SS patients were chosen from a larger group of SS patients $(n=66)$ based on the presence of ectopic germinal centres (GC) in 15 SS LSBs studied. All the MD patients were chosen on the basis of their elevated IgG4. The SS patients were chosen on the basis of ectopic GC in their biopsies. The mRNA expression of IL-21 and BCL-6 was significantly higher in $\mathrm{MD}$ than in SS labial salivary gland biopsies. The IL-21 was detected by immunohistochemistry in and around GC only in the $\mathrm{MD}$ patients. These results were consistent with the hypothesis that follicular T-helper cells (Tfh) play a key role in the formation of GC in $\mathrm{MD}$. By contrast, IL-17 was not found in either SS or MD. This article extends a recent study by the same group ${ }^{2}$ in Kyushu that distinguished $\mathrm{MD}$ and SS by showing elevation of Th2 and Tregs (ie, IL4, IL10 and FoxP3 expression by immunohistochemistry); and IgG4 plasma cells in the MD labial biopsies. Over the past decade, this group has published a number of excellent papers on IgG4-related diseases, including sclerosing cholangitis, multicentric Castleman's disease and other lymphoproliferative disorders. $^{3-5}$

The article is carefully presented by experts in the field, but is a bit confusing to the practicing rheumatologist due to the myriad of different cytokines and

Scripps Memorial, La Jolla, California, USA

Correspondence to Dr Robert Irving Fox, Scripps Memorial, Suite \#911 9850 Genesee Ave, \#910, La Jolla, CA 92037, USA; robertfoxmd@mac.cm receptors described. Several key issues for the general rheumatologist include:

A. What is the relationship between Japanese MD patients (now called IgG4-related dacroadenitis) and $\mathrm{MD}$ patients outside Japan?

B. What is the relationship of the IgG4-related $\mathrm{MD}$ dacroadenitis patients and SS patients in Japan?

C. What is the significance of finding $\mathrm{MD}$-like lesions in biopsies of SS patients, as these lesions have been reported over the past 50 years; ${ }^{67}$ are we dealing with a characteristic IL-21-based process or a different pathogenesis leading to a similar histopathology?

$\mathrm{MD}$ was originally considered to be a subtype of SS, based on histopathologic similarities between the two diseases. ${ }^{8} 9$ The term refers to a 'benign' lymphoepithelial lesion of the parotid and/or lacrimal glands. The name was originally derived from Jan Miculicz-Radeck, the Polish surgeon who described these conditions in $1892 .{ }^{10}$ There is a marked lymphoplasmacytic infiltration of the glands. Lymphoid follicles surround solid epithelial nests, giving rise to the 'epimyoepithelial islands' that are mainly composed of degenerating ductal and myoepithelial cells. ${ }^{11}$ Excess hyaline basement membrane material is deposited between cells, and there is also acinar atrophy and destruction. When the myoepithelail islands were found in a biopsy, it was felt that an inflammatory disease was more likely than a lymphoma. ${ }^{12}$

After Mikulicz's initial report of pathologic specimens, biopsies with similar dense lymphoid infiltrates and myoepithelial islands were reported in association with other diseases, such as tuberculosis, sarcoidosis, lymphoma ${ }^{13}$ and, subsequently, a similar pathology was noted in parotid biopsies from HIV-infected patients. ${ }^{14}$ Thus, the term Mikulicz syndrome fell out of favour by the 1930 s as lacking specificity. ${ }^{13}$ Indeed, the report by Henrik Sjogren in $1933^{15}$ described a more limited spectrum of patients with lymphoid infiltrates of salivary and lacrimal glands associated with keratoconjunctivitis sicca (KCS) and by excluding the above conditions; his initial reports were largely ignored in the medical literature for the next 20 years. The term SS gained a rebirth after pathologic reports by Morgan in $1953,{ }^{13}$ and a New England Journal clinical pathology conference (CPC case) in 1954; ${ }^{16}$ literally, the diagnosis of SS was 'rediscovered' 20 years after the initial reports by Sjogren, since the initial report was not translated from the German literature.

Benign lymphoepithelial lesions labelled as $\mathrm{MD}$ (in patients lacking features of SS) were initially reported predominantly in Caucasion males around 50 years of age. ${ }^{16}$ In this study of IgG4 MD from Japan, the majority of patients $(66 \%)$ were female. The lesions were usually unilateral in previous reports of Caucasian patients, and the symmetry of lesions is not specified in the present report from Japan. In the initial $\mathrm{MD}$ reports by Mikulicz, some patients with biopsies containing lymphoepithelial lesions had clinical features of $\mathrm{KCS}^{16}$ When KCS features were present, the swelling was usually bilateral, and patients were predominantly female with a slightly younger age distribution. ${ }^{13}$ The concept of 'benign' lymphoepithelial lesion was later questioned, ${ }^{12}$ since $\mathrm{MD}$ patients among Caucasian patients were uniformly found to have clonal immunoglobulin rearrangements and elevated frequency of lymphoma. ${ }^{17}$ The monocytic B-cell infiltrates in the SS biopsies with myoepithelial lesions exhibited IgM clonal rearrangements. ${ }^{18}$ Thus, the IgG4 MD patients in Japan may represent a distinct subgroup from non-Japanese $\mathrm{MD}$ patients previously reported. ${ }^{12}$ Only future reports of non-Japanese $\mathrm{MD}$ patients will allow us to make comparisons.

Maehara et al present an elegant 'bench to bedside' translation of molecular biology to histology. ${ }^{1}$ Due to the preferential and characteristic localisation of lymphoid infiltrates in the lacrimal and parotid glands, either vascular adhesion molecules or their ligands must direct the 'homing' of lymphocytes. In the IgG4-related $\mathrm{MD}$ reported in this article, the homing receptor seems to involve CXCR5. Their particular histologic organisation into their ectopic GC appears to involve Th2 cells (IL-4 and Tregs), ${ }^{2}$ follicular T-helper cells and IL-21.

By contrast, SS biopsies of salivary glands (in Europe) exhibit CXCL and 
type 1 interferon signature. ${ }^{20}$ In a recent paper by the same group (Tanaka et $a l^{2}$ ), a different pattern of adhesive molecules was shown in IgG4 $\mathrm{MD}$ and SS. Similarly, the cytokine expressions (IL-21 and IL-6) also differ between the MD and SS patients in their cohort. Thus, IgG4 $\mathrm{MD}$ and SS patients in Japan differ in the factors that initiate and maintain the lymphoid infiltrates as well as the clinical features of each group.

A key issue for western rheumatologists is the association of IgG4 with $\mathrm{MD}$, SS or sclerosing cholangitis in our practice. Little hard data exist on the global incidence and prevalence of IgG4-related disease, including $\mathrm{MD}$ or $\mathrm{SS}^{21}$ Virtually all studies, including the present study, pertain to the disease in Japan. Although it has been a decade since the IgG4related diseases were reported from Japan, there remains a paucity of reports of IgG4-related disease from other parts of the world. ${ }^{21}$ It may be that particular environmental and epigenetic factors in Japan cause immunologically predisposed individuals to develop these particular histologic responses. By analogy, an unusual variant of SS is found in Kyushu (Japan), and was later found to be due to a variant of HTLV-1 viral infection. ${ }^{22}$

In summary, Maehara et al have extended their previous papers on IgG4-related MD. ${ }^{1}$ IgG4 $\mathrm{MD}$ in Japan is clinically and pathogenetically distinct from SS in the same geographic region. Although some biopsies from SS patients contain histologic features of myoepithelial islands and ectopic GC, the pathogenetic processes leading to this histopathology are distinct from IgG4 MD. The frequency of IgG4-related $M D$ in regions outside Japan remains unknown, and so, it is difficult to assess the significance of these findings in our $\mathrm{MD}, \mathrm{SS}$ or sclerosing cholangitis patients. Nevertheless, it is an elegant study in describing the factors leading to a particular pathologic biopsy in a group of Japanese patients. For the readers, it is time to urge our pathologists to review our $\mathrm{MD}$ cases and determine the relationship with the patients in this study.

\section{Competing interests None.}

Provenance and peer review Commissioned; externally peer reviewed.

Accepted 8 September 2012

Ann Rheum Dis 2012;71:1919-1920.

doi:10.1136/annrheumdis-2012-201866

\section{REFERENCES}

1. Maehara T, Moriyama M, Nakashima $\mathrm{H}$, et al. Interleukin-21 contributes to germinal centre formation and immunoglobulin G4 production in lgG4-related dacryoadenitis and sialoadenitis, so called Mikulicz's disease. Ann Rheum Dis 2012;71:2011-19.

2. Tanaka A, Moriyama M, Nakashima $H$, et al. Th2 and regulatory immune reactions contribute to $\lg \mathrm{G} 4$ production and the initiation of Mikulicz disease. Arthritis Rheum 2012;64:254-63.

3. Masaki Y, Dong L, Kurose N, et al. Proposal for a new clinical entity, IgG4-positive multiorgan lymphoproliferative syndrome: analysis of 64 cases of IgG4-related disorders. Ann Rheum Dis 2009;68:1310-5.

4. Sato Y, Kojima M, Takata K, et al. Systemic IgG4-related lymphadenopathy: a clinical and pathologic comparison to multicentric Castleman's disease. Mod Pathol 2009;22:589-99.

5. Hamano H, Kawa S, Horiuchi A, et al. High serum IgG4 concentrations in patients with sclerosing pancreatitis. N Engl J Med 2001;344:732-8.

6. Fishleder A, Tubbs R, Hesse B, et al. Uniform detection of immunoglobulin-gene rearrangement in benign lymphoepithelial lesions. N Engl J Med 1987;316:1118-21.

7. Morgan WS. The probable systemic nature of Mikulicz's disease and its relation to Sjögren's syndrome. N Engl J Med 1954;251:5-10.

8. Yamamoto M, Takahashi $\mathrm{H}$, Sugai S, et al. Clinical and pathological characteristics of Mikulicz's disease (lgG4-related plasmacytic exocrinopathy). Autoimmun Rev 2005;4:195-200.

9. Yamamoto $\mathbf{M}$, Takahashi $\mathrm{H}$, Ohara $\mathbf{M}$, et al. A new conceptualization for Mikulicz's disease as an
IgG4-related plasmacytic disease. Mod Rheumatol 2006;16:335-40.

10. Mikulicz JH. Uber eine eigenartige symmetrische Erkrankung der Tranen- und Mundspeicheldrusen. In: Billroth GT, ed. Beitr Chir Fortschr Stuttgart 1892:610-30.

11. Dardick I, Rippstein P, Skimming L, et al. Immunohistochemistry and ultrastructure of myoepithelium and modified myoepithelium of the ducts of human major salivary glands: histogenetic implications for salivary gland tumors. Oral Surg Oral Med Oral Pathol 1987;64:703-15.

12. Batsakis JG, Bernacki EG, Rice DH, et al. Malignancy and the benign lymphoepithelial lesion. Laryngoscope 1975;85:389-99.

13. Morgan W, Castleman B. A clinicopathologic study of Mikulicz'a disease. Am J Pathol 1953;29. 471-503.

14. Ulirsch RC, Jaffe ES. Sjögren's syndrome-like illness associated with the acquired immunodeficiency syndrome-related complex*. Hum Pathol 1987; 18:1063-8.

15. Sjögren HS. Zur kenntnis der keratoconjunctvitis sicca (Keratitis folliformis bei hypofunktion der tranendrusen). Acta Opthalmol (Copenh) 1933;2:1-151.

16. Morgan WS. The probable systemic nature of Mikulicz's disease and its relation to Sjögren's syndrome. N Eng J Med 1954;251:5-9.

17. Fishleder A, Tubbs $R$, Hesse $B$, et al. Immunoglobulin-gene rearrangement in benign lymphoepithelial lesions. N Engl J Med 1987;316 1118-21.

18. Shin SS, Sheibani K, Fishleder A, et al. Monocytoid B-cell lymphoma in patients with $\mathrm{Sj} \sqrt{ }$ dgren's syndrome: a clinicopathologic study of 13 patients. Hum Pathol 1991;22:422-30.

19. Diehl SA, Schmidlin H, Nagasawa M, et al. STAT3-mediated up-regulation of BLIMP1 Is coordinated with BCL6 down-regulation to control human plasma cell differentiation. $\mathrm{J}$ Immunol 2008;180:4805-15.

20. Hjelmervik TOR, Petersen K, Jonassen I, et al. Gene expression profiling of minor salivary glands clearly distinguishes primary Sjögren's syndrome patients from healthy control subjects. Arthritis Rheum 2005;52:1534-44.

21. Stone JH, Zen Y, Deshpande V. IgG4-Related Disease. N Engl J Med 2012;366:539-51.

22. Ohyama $\mathbf{Y}$, Nakamura $\mathrm{S}$, Hara $\mathrm{H}$, et al. Accumulation of human T Iymphotropic virus type I, Äêinfected T cells in the salivary glands of patients with human T lymphotropic virus type I, Äêassociated Sjögren's syndrome. Arthritis Rheum 1998;41:1972-8. 